\title{
SOURDOUGH BREAD FROM THE BLEND OF CASSAVA, SWEET POTATO, AND SOYBEAN FLOURS USING LACTOBACILLUS PLANTARUM AND PICHIA KUDRIAVZEVII
}

\author{
K. Banwo*, O. Osagbemi, O. Ajao and A. Sanni \\ Department of Microbiology, University of Ibadan, Oyo state, Nigeria
}

(Received: 27 March 2020; accepted: 2 June 2020)

\begin{abstract}
Sourdough is specialty bread made from a combination of flour, lactic acid bacteria, and yeasts. Composite flour of cassava, sweet potato, and soybean was used for the production of sourdough bread employing autochthonous lactic acid bacteria and yeasts isolated from the composite dough. The flour samples were assessed for functional properties, while the sourdough breads were evaluated for nutritional composition and organoleptic properties. The flour samples possessed good proximate profiles and phenolic contents. The lactic acid bacterium and yeast with the most desirable properties were identified as Lactobacillus plantarum and Pichia kurdriazevii. Fermentation improved the nutritional indices of the composite sourdough bread samples. Lactobacillus plantarum SLC21 and $P$. kudriavzevii SYD17 bread had a shelf life of 7 days, while the control bread lasted for at least 4 days. Lactobacillus plantarum SLC21 and Pichia kudriavzevii SYD17 bread had the best overall acceptability. Utilisation of these local crops in a composite blend for sourdough will increase commercial profit for local farmers and developing economy. The composite blend will be of great importance in the preparation of pastries that do not require high gluten content. The strains exhibited great potentials for a better nutritional composition of the composite sourdough bread.

Keywords: composite flour, gluten-free, wheat alternatives, lactic acid bacteria, yeasts
\end{abstract}

Sourdough is a product of bread comprising a mixture of flour, water, and actively growing cultures of mainly lactic acid bacteria (LAB) and yeasts in a traditional practice (VAN KERREBROECK et al., 2017). Although both lactic acid bacteria and yeasts are usually involved in a synergistic relationship, the major function of lactic acid bacteria is acidification and flavour development, while yeast is primarily involved in leavening. Sourdough bread is a specialty bread that can be produced from either wheat flour or wheat flour fortificated with non-wheat flour samples. This is one of the best features of the process, because it allows the baker to make bread with indigenous ingredients, even those that cannot be processed individually, and this mixture is known as composite flour (NOORFARAHZILAH et al., 2014). The use of composite flours in bread making holds a promise in development of nutritive value and quality of bread products, which is a concept gaining acceptance in the developing countries. Of particular interest is the use of pseudocereals such as teff, millet, sorghum, and quinoa in bakery products formulations, which improves nutritional features and adds distinctive flavour to the food products (Di RENZO et al., 2019). Although not widely available, consumer acceptability of products made with composite flour have been well acknowledged in many parts of the world (EDEMA \& SANNI, 2008). The use of composite flour derived from tubers and legumes act as a gluten-free substrate, which could serve as an alternative towards improved bread product. Legumes had been successfully used in the production of baked

\footnotetext{
* To whom correspondence should be addressed.

Phone: +234 8056100840; e-mail: kolabanwo@yahoo.com
} 
products (MoHAmmed et al., 2012; KoHAJDova et al., 2013). Soy is a good source of certain microelements and contains the majority of the nutrients needed for a healthy living, however, it comprises some antinutritional factors. Sweet potato and cassava undergo post-harvest spoilage in many parts of the sub-Saharan Africa, where the crops are grown. Therefore, in addition to the conventional food products made from these crops, sourdough bread can be included and be a sustainable healthy food for people suffering from celiac disease. Legumes, cassava, and other tuber crops can be substitutes for the major raw materials in bread making because of the abundance of these crops in all regions of Nigeria and sub-Saharan Africa. Cassava flour and other substrates are well studied in the making of composite flour bread (MoHammed et al., 2012; NoOrfarahziLAH et al., 2014). The physicochemical properties of composite flours have been found to be similar to those of wheat flour and are likely to have the potential to replace it (VAN KerREBroeccK et al., 2017). The replacement of wheat flour with cassava flour at $30 \%$ and $20 \%$ in some studies produced acceptable bread when compared with $100 \%$ wheat flour. The addition of full-fat and defatted soy flour at $7-30 \%$ have been reported to produce an acceptable bread with qualities comparable to bread made with $100 \%$ wheat flour (AYELE et al., 2017). However, there is little information on the use of starter cultures in the previous reports on bread making from composite flour. Therefore, this study was aimed at using lactic acid bacterium and yeast associated with fermenting cassava, sweet potato, and soybean flour as starter cultures in the production of sourdough bread and the determination of some functional properties of bread made from this composite flour.

\section{Materials and methods}

\subsection{Sample collection and preparation}

Raw materials were purchased from a retail market in Ibadan, South-West Nigeria. Four hundred grammes of cassava and sweet potato tubers were peeled, washed, chopped into bits, sun-dried, milled to flour using a hammer mill, and sieved using 0.2-0.25 mm mesh. Three hundred grams of soybean were sorted/hand-picked before roasted to light brown, boiled for 20 min, decortified, drained for about 30 min, then sun-dried and milled (EDEMA \& SANNI, 2008). All dry milled flours were stored in airtight jars until use.

\subsection{Proximate analyses of the flour samples}

Proximate content of the flour from sweet potato, cassava, and soybean were determined on dry matter basis. Carbohydrate $(\%)=100-($ sum of the percentage for ash, fat, protein, and crude fibre) (AOAC, 2010; OGUNSAKIN et al., 2015; 2017).

\subsection{Water absorption capacity and bulk density of the flour samples}

The water absorption capacity was calculated in percentage of the water bound per gram of flour, and bulk density was determined and recorded as grams per millilitre $\left(\mathrm{g} \mathrm{m}^{-1}\right)$ (FALADE \& OKAFOR, 2015).

\subsection{Total soluble phenolic content of the flours}

The determination of total soluble phenolics was carried out using the Folin-Ciocalteau assay. Standard curves were established using various concentrations of gallic acid (10-300 $\mu \mathrm{g} \mathrm{ml}^{-1}$ ) in $95 \%$ ethanol (SHETTY et al., 1995). 


\subsection{Microbial isolation from composite flour}

The cassava, sweet potato, and soybean flours were mixed in the ratio 1:1:1 (weight per volume), respectively, in tap water, and then the blend was allowed to ferment at room temperature. Microbial isolation was carried out at $12 \mathrm{~h}$ intervals for $48 \mathrm{~h}$.

\subsection{Microbiological analyses of the fermenting flour}

Microbial isolation was carried out on de Man Rogosa Sharpe medium (MRS) (LAB M, Lancashire, U.K) adjusted to $\mathrm{pH} 5.4$ for lactic acid bacteria and on Malt extract agar (MEA) (LAB M, U.K) for yeasts. Representative colonies were purified by sub-culturing until pure cultures were obtained. Pure cultures were maintained on agar slants at $4{ }^{\circ} \mathrm{C}$.

1.6.1. Characterisation and identification of microbial isolates. The characterisation of lactic acid bacteria (LAB) and yeasts was done as described by HARRIGAN and MCCANCE (1976) and KURTZMAN and co-workers (2011), respectively.

\subsection{Selection of starter cultures from lactic acid bacteria and yeast isolates}

The criteria for selection of starter cultures based on the acid equivalent value of the strains and the antifungal activities against Aspergillus flavus (EDEma \& SANNI, 2008).

1.7.1. Genotypic characterisation of the selected isolates. The genomic DNA of the LAB and yeasts was extracted. The partial 16S rRNA nucleotide sequence was amplified by PCR, where the forward primer was LbF (5'-GAG TTT GAT CCT GGC TCA G-3') and the reverse was LbR (5'-AGA AAG GAG GTG ATC CAG CC-3') (BANWO et al., 2012) for LAB, while for the yeasts ITS 4 (5'-TCC TCC GCT TAT TGA TAT GC-3') and ITS 5 (5'GGA AGT AAA AGT CGT AAC AAG G-3') (White et al., 1990) were used. The PCR products of $\mathrm{LAB}$ and yeasts were cleaned using spin columns and sequenced in commercial laboratories. The sequences were submitted to the Genbank and accession numbers were assigned to them.

\subsection{Preparation of starter inoculated fermented dough and bread making}

1.8.1. Studies on the starter culture fermented sourdough bread. Cassava flour (150 g), sweet potato flour $(100 \mathrm{~g})$, and soybean flour $(50 \mathrm{~g})$ were mixed with water $(250-300 \mathrm{ml})$, baking fat (10 g), sugar (30 g), salt (1 g), and egg (1 whole egg). The dough was prepared and inoculated with the starter organisms in sterile distilled water with an inoculum size of about $2 \times 10^{9} \mathrm{CFU} \mathrm{m} \mathrm{m}^{-1}$ for LAB and $3 \times 10^{9} \mathrm{CFU} \mathrm{ml}^{-1}$ for yeasts. The strains were used individually and as mixed cultures in the fermentation of the combined flour, while $2.5 \%$ of baker's yeast was used as control. The dough with the baker's yeast was left for $45 \mathrm{~min}$, while the starter culture leavened doughs were left for $6 \mathrm{~h}$, and all were baked at $180-200{ }^{\circ} \mathrm{C}$ for $45-60 \mathrm{~min}$ (OGunsakin et al., 2015).

\subsection{Proximate analyses of the sourdough bread samples}

The starter culture sourdough bread samples were assayed as described above (AOAC, 2010; OGUNSAKIN et al., 2015; 2017). 


\subsection{Determination of vitamin and mineral contents of the sourdough bread samples}

Samples were taken from the bread and analysed for the vitamins A, $\mathrm{B}_{2}, \mathrm{C}$, and E. Minerals such as calcium, potassium, and iron were analysed using atomic absorption spectrophotometry (Thermo Fisher Scientific, Massachusetts, USA), while phosphorus was measured on a Technicon autoanalyser EFI 201 (Technicon Instruments, Bellevue, USA) (AOAC, 2010; OGUNSAKIN et al., 2015).

\subsection{Sensory evaluation of the sourdough bread samples}

The organoleptic assessment of the bread was carried out within $24 \mathrm{~h}$ of baking by a 20-man untrained panel of ten women and ten men with age 28-54 in the evaluation of sourdough breads. They evaluated the bread samples on a 9-point hedonic scale for colour, taste, texture, aroma, crumb, and overall acceptability (OGUNSAKIN et al., 2015).

\subsection{Analyses of data}

The values were expressed as mean \pm standard deviation (SD), where $n=3$. The results were calculated by one-way Analysis of Variance (ANOVA) statistical method (Statistical Analysis System version 9.2 programme, SAS Inc., USA (2008). Mean values were separated using Duncan's multiple range test. Statistical differences were established at $\mathrm{P} \leq 0.05$ (GoMEZ \& Gomez, 1984).

\section{Results and discussion}

\subsection{Proximate content and functional characteristics of the flour samples}

The proximate composition and functional properties of the flour samples are shown in Table 1. The moisture content of all flour samples was less than $10 \%$. As reported by KoHAJDOva and co-workers (2013), flours with moisture content less than 13\% are safer from moisturedependent spoilage. Soybean flour had the highest crude fat content, while sweet potato the lowest. Fat content plays a significant role in the shelf-life of flour (OHIZUA et al., 2017). The water absorption capacities of the flours may be attributed to the low protein and high carbohydrate contents of flour, as this has a significant impact on the water absorption capacity of foods. The flours can be used as ingredients in soups and gravies (KoHAJDOVA et al., 2013; OHIZUA et al., 2017). The bulk density is used to assess flour heaviness, storage, and transport properties, as with a lower bulk density, a lower amount may be packaged within a constant volume (OHIzUA et al., 2017). The composite flours maybe used as thickners, because high bulk density flours are used as thickeners in food (FALADE \& OKAFOR, 2015). The total soluble phenolic content of the flour samples implies that there is liberation of bioactive compounds, which can enhance the quality of the food products made from these flours. Soybean flour is essential for the integration of health supporting bioactive compounds like isoflavones, used in nutrient fortification (AYELE et al., 2017).

\subsection{Selection of starters for the production of sourdough from composite flour}

The lactic acid bacterium was identified as Lactobacillus plantarum SLC21 (KX943327), while the yeast as Pichia kudriavzevii SYD17 (MK290829). The multifaceted interaction between the flour used and the process conditions applied may have impact on the dominant microorganisms that are most adapted to that environment (VAN KERREBROECK et al., 2017). For the production of sourdough bread, batter method was used, because non-wheat flours do not form satisfactory dough, but show improved performance when prepared in the form of batter and the starter culture is used as in controlled fermentation (EDEMA \& SANNI, 2008). 


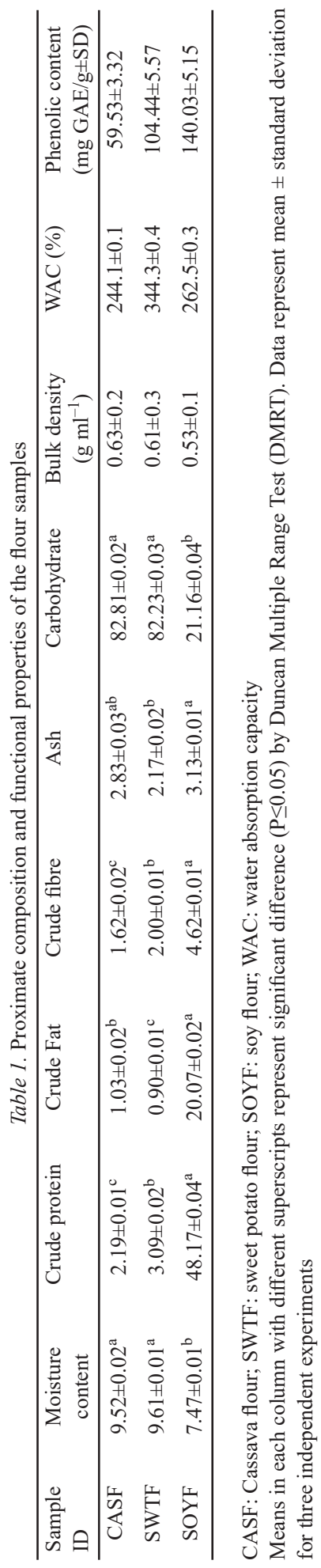




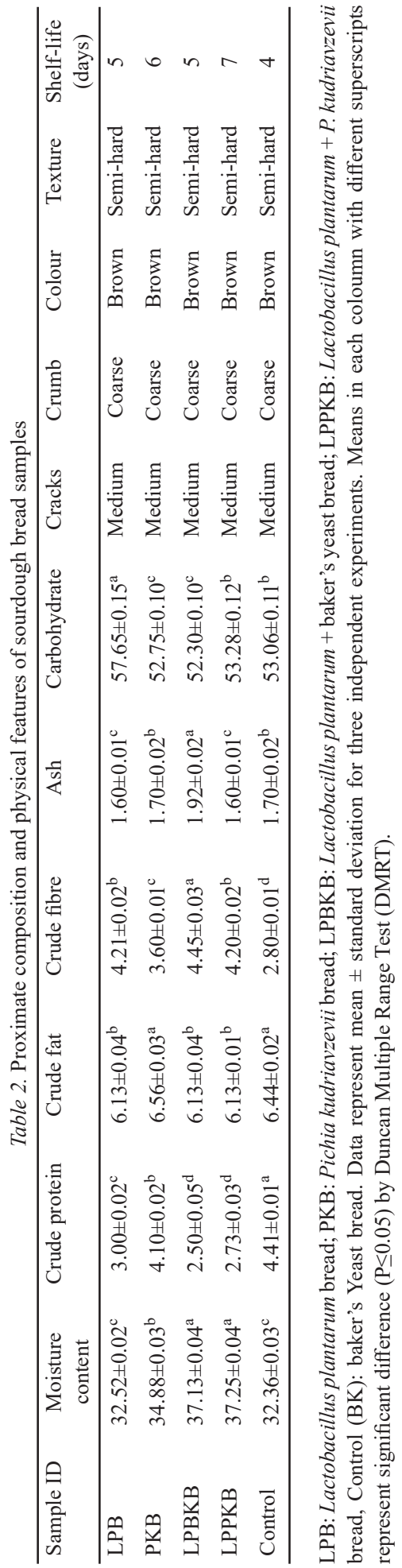




\subsection{Proximate composition and physical features of the sourdough bread samples}

The proximate composition and physical features of the sourdough bread samples are presented in Table 2. The carbohydrate and fibre contents of the flour and bread samples indicate that the composite blend leavened with starter cultures is a good source of fibre, and can be used in the production of functional food products. Constant intake of food with high fibre content has been linked to the reduction of diabetes, obesity, and haemorrhoids (OHIZUA et al., 2017). The crude fat of the starter culture leavened bread samples is low, which makes the bread samples suitable choice of food for the elderly. Soybean contributed to the high ash contents of the sourdough bread due to high mineral contents (AYELE et al., 2017). All bread samples had medium crack, dark brown crust, and semi-hard texture. The longest shelf life of 7 days was recorded for LPPK bread, while the shortest of 4 days was observed for the control bread. OGUNSAKIN and co-workers (2015) suggested that the prolonged shelf life is due to homofermentative lactic acid bacteria producing mainly lactic acid and not carbon dioxide. However, in the study of EDEMa and SANNI (2008), shelf life increased for up to seven days in sour-maize bread.

\subsection{Vitamin and mineral composition of the sourdough bread samples}

The vitamin and mineral compositions of the bread samples is displayed in Table 3 . The bread samples contained vitamins $\mathrm{A}, \mathrm{E}, \mathrm{B}_{2}$, and $\mathrm{C}$. The presence of vitamin $\mathrm{A}$ in the samples helps the maintenance of healthy skin and fighting infections. Vitamin $\mathrm{E}$ aids formation of red blood cells, while vitamin $\mathrm{B}_{2}$ is involved in the metabolism of carbohydrates. Vitamin $\mathrm{C}$ aids rapid wound healing, its deficiency can cause weakness (CHARLES et al., 2004). The calcium content observed in this study is higher than that of other staple crops, ranging between 15 and $35 \mathrm{mg} / 100 \mathrm{~g}$ (AyELE et al., 2017). The range of potassium and phosphorus contents of the bread samples varied considerably. Potassium and phosphorus are essential minerals in the development and maintenance of tissues and nerves and the physiological stimulation of the body (OHIzUA et al., 2017). The results of high iron content indicate that bread from the composite flour is considered a good source of iron. The vitamins and minerals are essential to the normal functioning of the body, the composite bread meets the standard requirements as seen in the recommended daily intake indicated in Table 3.

\subsection{Sensory attributes of the sourdough bread samples}

The result of sensory properties of the bread samples is shown in Figure 1. The LPPK bread displayed the best sensory values with its exceptional organoleptic characteristics. Yeasts are important microorganisms in a good batter for leavening, while LAB produce acids and other metabolites adding to the aroma and taste (EDEMA \& SANNI, 2008). Bread leavened with baker's yeast only had the lowest sensory values. This is in agreement with the study of OGUNSAKIN and co-workers (2015). This maybe due to the amount of alcohol produced in the sourdough during fermentation. Sensory assessment of sourdough bread is not definite, because consumers have diverse taste inclinations and sourdough is a special bread with different qualities than conventional bread (OGUNSAKIN et al., 2015). 


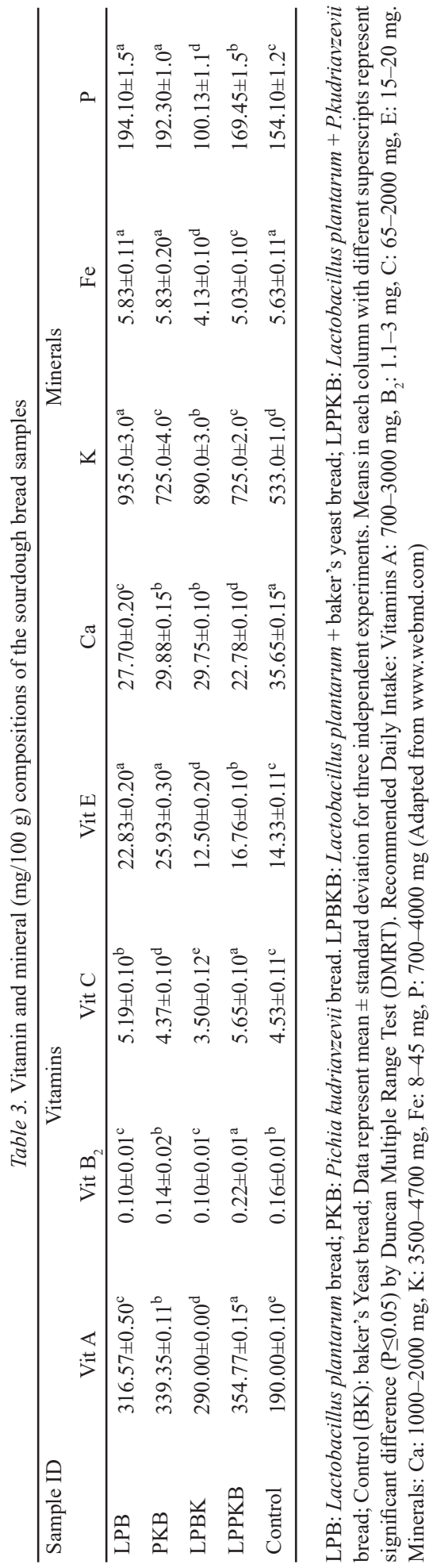




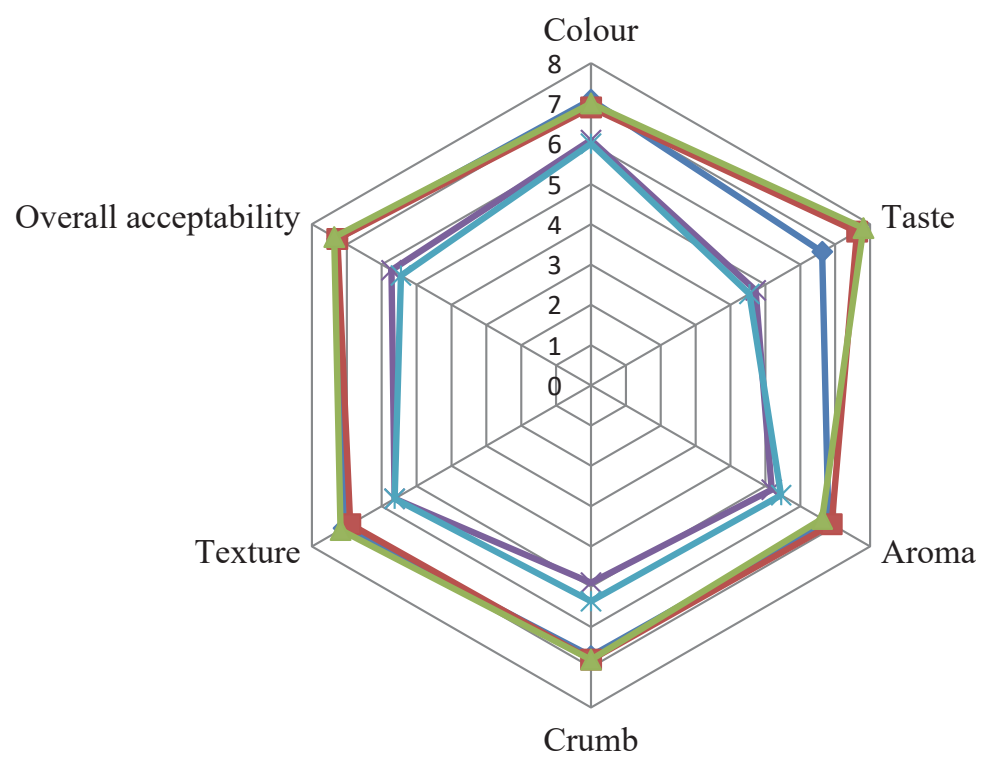

Fig. 1. Sensory evaluation of the sourdough bread samples

LPB: Lactobacillus plantarum bread; PKB: Pichia kudriavzevii bread; LPBKB: Lactobacillus plantarum + baker's yeast bread; LPPKB: Lactobacillus plantarum + P. kudriavzevii bread; Control (BK): baker's yeast bread.

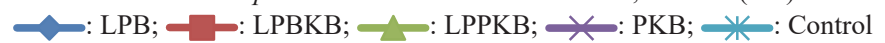

\section{Conclusions}

In conclusion, this study elucidated the properties of sourdough from the composite flour of cassava, sweet potato, and soybean. The results facilitated the selection of autochthonous starter cultures from the fermenting composite sponge and necessitated consideration of different substrates for the production of bread. In addition to the nutritional and gluten-free properties, the composite blend of cassava, sweet potato, and soybean holds the potential for the replacement of wheat in bread making. These breads can be great components of a balanced and healthy diet.

The authors appreciate Prof. Yin Li and Mr. Liangtan Miao of the Centre of Excellence for Biotechnology, Institute of Microbiology, Chinese Academy of Sciences for the molecular characterisation of the lactic acid bacterium strain and Bioscience Centre, International Institute for Tropical Agriculture, Ibadan for the sequencing of the yeast strain used in this study.

\section{References}

AOAC (2010): Methods of the association of official chemists. Official methods of analysis, $25^{\text {th }}$ ed. AOAC, Virginia, USA. p. 1141.

Ayele, H.H., Bultosa, G., Abera, T. \& Astatkie, T. (2017): Nutritional and sensory quality of wheat bread supplemented with cassava and soybean flours. Cogent Food Agric., 3, 1-13.

Banwo, K., SAnni, A.I., TAN, H.R. \& Tian, Y.Q. (2012): Phenotypic and genotypic characterization of lactic acid bacteria isolated from some Nigerian traditional fermented foods. Food Biotechnol., 26(2), 124-142. 
Charles, A.L., Chang W.K., Sriroth, K. \& Huang, T. (2004): Some physical and chemical properties of starch isolates of cassava genotypes. Starch, 56, 413-418.

Di Renzo, T., Reale, A., Boscaino, F. \& Messia, M.C. (2019): Flavoring production in Kamut $₫$, quinoa and wheat doughs fermented by Lactobacillus paracasei, Lactobacillus plantarum, and Lactobacillus brevis: ASPMEGC/MS study. Front. Microbiol., 9, 429.

EDEma, M.O. \& SANNI, A.I. (2008): Functional properties of selected starter cultures for sour maize bread. Food Microbiol., 25, 616-625.

FaLAde, K.O. \& OKafor, C.A. (2015): Physical, functional and pasting properties of flours from corms of two cocoyam (Colocasia esculenta and Xanthosoma sagittifolium) cultivars. J. Food Sci. Tech., 52(6), 3440-3448.

Gomez, K.A. \& GomeZ, A.A. (1984): Statistical procedures for agricultural research $\left(2^{\text {nd }}\right.$ ed). John Wiley \& Sons, New York, p. 630.

Harrigan, W.F. \& MCCANCE, M.E. (1976): Laboratory methods in food and dairy microbiology. Academic Press Inc., London.

Kohajdova, Z., Karovičova, J. \& Magala, M. (2013): Effect of lentil and bean flours on rheological and baking properties of wheat dough. Chem. Pap., 67(4), 398-407.

Kurtzman, C.P., Fell, J.W. \& Boekhout, T. (2011): The yeasts: A taxonomic study, $5^{\text {th }}$ ed. Vol. 3. Elsevier Science Publishers, Amsterdam. 2354 pages.

Mohammed, I., Ahmed, A.R. \& Senge, B. (2012): Dough rheology and bread quality of wheat-chickpea flour blends. Ind. Crop. Prod., 36,196-202.

Noorfarahzilah, M., Lee, J.S., Sharifudin, M.S., Mohd Fadzelly, A.B. \& HaSmadi, M. (2014): Applications of composite flour in development of food products. Int. Food Res. J., 21(6), 2061-2074.

Ogunsakin, A.O., Banwo, K., Ogunremi, O.R. \& Sanni, A.I. (2015): Microbiological and physico-chemical properties of sourdough bread from sorghum flour. Int. Food Res. J., 22(6), 2610-2618.

Ogunsakin, A.O., Vanajakshi, V., Anu-Appaiah, K.A., Vijayendra, S.V.N, Walde, S.G., ... \& Prabhasankar, P. (2017): Evaluation of functionally important lactic acid bacteria and yeasts from Nigerian sorghum as starter cultures for gluten-free sourdough preparation. LWT - Food Sci.Technol., 82, 326-334.

Ohizua, E.R., Adeola, A.A., Idowu, M.A., Sobukola, O.P., Afolabi, T.A., ... \& Falomo, A. (2017): Nutrient composition, functional, and pasting properties of unripe cooking banana, pigeon pea, and sweetpotato flour blends. Food Sci. Nutr., 7, 1-13.

Shetty, K., Curtis, O., Levin, R., Witkowsky, R. \& AnG, W. (1995): Prevention of vitrification associated with in vitro shoot culture of oregano (Origanum vulgare) by Pseudomonas spp. J. Plant Physiol., 147, 447-451.

Van Kerrebroeck, S., Maes, D. \& De Vuyst, L. (2017): Sourdoughs as a function of their species diversity and process conditions, a meta-analysis. Trends Food Sci. Tech., 68, 152-159.

White, T.J., Bruns, T., LeE, S. \& TAYLOR, J. (1990): Amplification and direct sequencing of fungi ribosomal RNA genes for phylogenetics. -in: InNis, M.A., Gelfand, D.H., Sninsky, J.J. \& White, T.J. (Eds) PCR protocols. A guide to methods and applications. Academic Press, San Diego. pp. 315-322. 